\title{
Determination of the Elastic/Plastic Transition of Human Enamel by Nanoindentation
}

\author{
Siang Fung Ang ${ }^{1}$, Torben Scholz ${ }^{1}$, Arndt Klocke ${ }^{2,3}$, Gerold A. Schneider ${ }^{1 *}$ \\ ${ }^{1}$ Institute of Advanced Ceramics, Hamburg University of Technology, Denickestr. 15, Hamburg \\ 21073 Germany \\ ${ }^{2}$ Division of Orthodontics, Department of Orofacial Sciences, University of California, \\ San Francisco, CA 94143, USA \\ ${ }^{3}$ Department of Orthodontics, University Medical Center Hamburg-Eppendorf, Martinistr. 52, \\ Hamburg 20246 Germany
}

\begin{abstract}
.
Objectives/Methods: From a materials scientist's perspective, dental materials used for tooth repair should exhibit compatible mechanical properties. Fulfillment of this criterion is complicated by the fact that teeth have a hierarchical structure with changing mechanical behavior at different length scales. In this study, nanoindentation with an $8 \mu \mathrm{m}$ spherical indenter was used to determine the elastic/plastic transition under contact loading for enamel.

Results: The indentation elastic/plastic transition of enamel at the length scale of several hundreds of hydroxyapatite crystallites, which are within one enamel rod, is revealed for the first time. The corresponding penetration depth at the determined indentation yield point of $1.6 \mathrm{GPa}$ and $0.6 \%$ strain is only $7 \mathrm{~nm}$. As a consequence of the small depth it is decisive for the experiment to calibrate the indenter tip radius in this loading regime. The elastic modulus of $123 \mathrm{GPa}$ was evaluated directly by the Hertzian penetration and not by the unloading part of the indentation curve.

Significance: We believe these data are also a valuable contribution to understand the mechanical behavior of enamel and to develop nanoscale biomimetic materials.
\end{abstract}

Keywords: calcified tissues, elastic/plastic transition, enamel, mechanical properties, nanoindentation, yield point

\section{INTRODUCTION}

Analysis of the mechanical properties of dental enamel is complex, due to its hierarchical structure. Dental enamel is the hardest structure in the human body with approximate $96 \mathrm{wt} \%$ hydroxyapatite [1]. At the microstructural level, it consists of closely-packed parallel rod-like structures also called prisms that span from the dentinoenamel junction (DEJ) to approximately 6-12 $\mu \mathrm{m}$ below the tooth surface [2]. These rods are enveloped by organic-rich sheaths. At the nanostructural level, the rods consist of hydroxyapatite crystallites with different orientations inside. Adult human enamel crystallites have roughly hexagonal forms and an average cross section of 24-35 nm in thickness, $55-90 \mathrm{~nm}$ in width [3,4]. The crystallites are at least $100 \mu \mathrm{m}$ long [5], and some investigators believe that they span over the entire thickness of the enamel layer [6]. Each crystallite is enveloped by an approximately $1 \mathrm{~nm}$ thick organic layer. The interpretation of the mechanical behavior of enamel, a biocomposite with different structural levels should be performed in correlation to its structural and compositional characteristics.

\footnotetext{
* Corresponding author. Tel.: +49 40 428783037; fax: +49 40 428782647.g.schneider@,tuhh.de. doi:10.1016/j.dental.2009.06.014
} 
Early investigations have focused on the mechanical characterization of whole teeth and larger size enamel samples on a macroscopic scale (Tab. 1). Parameters usually assessed were elastic modulus, the stress at the proportional limit and the compressive strength. The elastic modulus is a measure of stiffness, calculated from the ratio of compressive stress to strain from the initial linear region of a stress-strain curve. The stress at the proportional limit is the stress at the stress-strain curve where the curve starts to deviate from the linear stress-strain relationship. The compressive strength is the maximum compressive stress that a test specimen can withstand without failure. The strain at the proportional limit at different length scales, on the other hand, has received limited attention so far.

TABLE 1. Summary of documented compressive properties of enamel (loading direction is parallel with the enamel rod direction unless specified).

\begin{tabular}{|c|c|c|c|c|c|}
\hline Source & Sample type & $\begin{array}{c}\text { Elastic } \\
\text { modulus } \\
(\mathrm{GPa})\end{array}$ & $\begin{array}{c}\text { Proportional } \\
\text { limit strain } \\
(\%)\end{array}$ & $\begin{array}{c}\text { Proportional } \\
\text { limit stress } \\
(\mathrm{MPa})\end{array}$ & $\begin{array}{c}\text { Compressive } \\
\text { strength } \\
(\mathrm{MPa})\end{array}$ \\
\hline $\begin{array}{l}\text { Compression } \\
\text { test [10] }\end{array}$ & $\begin{array}{l}\text { Enamel cylindrical } \\
\text { pieces } \\
\text { Cusp } \\
\text { Side } \\
\text { Occlusal surface }\end{array}$ & $\begin{array}{l}48(5) \\
30(3) \\
9(5)\end{array}$ & $\begin{array}{l}0.5^{* *} \\
0.5^{* *} \\
1.3^{\text {** }}\end{array}$ & $\begin{array}{l}236(21) \\
146(28) \\
116(23)\end{array}$ & $\begin{array}{l}278(12) \\
195(15) \\
134(28)\end{array}$ \\
\hline $\begin{array}{l}\text { Compression } \\
\text { test [11] }\end{array}$ & $\begin{array}{l}\text { Enamel cylindrical } \\
\text { pieces } \\
\text { Cusp } \\
\text { Side } \\
\text { Side (transverse } \\
\text { rod) } \\
\text { Occlusal surface }\end{array}$ & $\begin{array}{l}46(5) \\
32(4) \\
10(3) \\
12(3)\end{array}$ & $\begin{array}{l}0.5^{* *} \\
0.6^{* *} \\
0.7^{* *} \\
0.8^{* *}\end{array}$ & $\begin{array}{l}224(26) \\
186(17) \\
70(22) \\
99(26) \\
\end{array}$ & $\begin{array}{l}261(41) \\
239(30) \\
95(32) \\
127(30)\end{array}$ \\
\hline $\begin{array}{l}\text { Axial } \\
\text { compression } \\
{[12]}\end{array}$ & $\begin{array}{l}\text { Enamel cylindrical } \\
\text { pieces } \\
\text { Cusp }(1 / d \geq 2) \\
\text { Side }(1 / d \geq 1.4)\end{array}$ & $\begin{array}{l}84(8) \\
78(5) \\
\end{array}$ & $\begin{array}{l}0.4^{* *} \\
0.4^{* *}\end{array}$ & $\begin{array}{l}353(78) \\
336(61) \\
\end{array}$ & $\begin{array}{l}384(86) \\
372(56) \\
\end{array}$ \\
\hline $\begin{array}{l}\text { Axial } \\
\text { compression } \\
{[8]}\end{array}$ & Whole tooth & - & $0.6^{*}$ & - & - \\
\hline $\begin{array}{l}\text { Spherical } \\
\text { indentation } \\
{[13]}\end{array}$ & $\begin{array}{l}\text { Polished tooth } \\
\text { exposing enamel }\end{array}$ & $83(0.8)$ & $0.5^{\#}$ & $290^{\star *}$ & $\begin{array}{c}330(40) \\
\text { (yield stress) }\end{array}$ \\
\hline $\begin{array}{l}\text { Nanoindentatio } \\
\mathrm{n} \text { with a } \\
\text { spheroconical } \\
\text { indenter } \\
\text { (present study) }\end{array}$ & $\begin{array}{l}\text { Polished cusp } \\
\text { exposing enamel of } \\
\text { a molar teeth }\end{array}$ & 123 & $\begin{array}{l}\varepsilon_{Y}=0.6 \\
(0.05)\end{array}$ & $\begin{array}{c}\sigma_{Y}=1600 \\
(100)\end{array}$ & - \\
\hline
\end{tabular}

"Estimated and averaged from the first linear region of graph(s) shown in the paper.

** Calculated from the relation, "stress at proportional limit" = "elastic modulus" $\times$ "strain at proportional limit"

\# Calculated by assuming that the proportional limit happened when plasticity began. 
(Standard deviations in italic form are calculated based on the formula $\sqrt{\frac{n \sum x^{2}-\left(\sum x\right)^{2}}{n^{2}}}$.)

When performing compression tests on a whole tooth by clamping grinded occlusal and apical ends, Neumann and DiSalvo observed two linear regions in a compressive load-deformation curve of a tooth [7]. The tooth hardened at the second linear region, which means a smaller deformation results from the same load increment (decreasing compressibility). The authors attributed decreasing compressibility at higher load to crystal reorientations under stress. Haines et al. measured the degree of shortening at a segment of mid-coronal enamel [8]. Both these authors and Fox [9] confirmed double linear regions as observed earlier. Besides deformation in the longitudinal direction, Haines et al. also observed that the tooth width did not change at smaller loads, but has a linear correlation at higher compressive loads [8]. They suggested that the higher compressibility at lower loads without change in width is caused by the fluid displacement inside enamel.

Besides compression tests on whole teeth, some investigators had undertaken considerable efforts to prepare cylindrical enamel specimens for compression tests [1012]. Samples from cusp tips gave highest mechanical properties probably due to the gnarled structure of enamel rods, whereas possible decalcification contributed to the lowest mechanical properties of samples prepared from occlusal surfaces [10]. Later, Staines et al. [13] performed indentation tests with a spherical indenter on enamel. They adopted the definition of yield stress as approximately $92 \%$ of the mean pressure exerted by the spherical indenter at the beginning of plastic flow from Timoshenko and Goodier [14]. Although not mentioned, the value of the strain when the plasticity began can be calculated. By using the method explained in the next section, from their reported penetration depth, $h_{t}=2 \mu \mathrm{m}$ and the indenter radius, $\mathrm{R}=3.175 \mathrm{~mm}$, a contact radius of $80 \mu \mathrm{m}$ is obtained which corresponds to an indentation strain of $0.5 \%$. Recently, He and Swain [15] used nanoindentation to derive enamel's indentation stress-strain curve. They utilized a spherical indenter radius of $10 \mu \mathrm{m}$, but due to the high load used (1-400 $\mathrm{mN})$, seemingly only the plastic part was revealed.

There are several shortcomings in our current state of knowledge on enamel properties from previous studies. Axial compression tests of enamel specimens on a macroscopic scale showed wide variations of more than $50 \%$ of the average value. The inconsistencies of such tests might originate from imperfections in the biomaterial itself and flaws in sample preparation methods.

Furthermore, enamel is a complex structure with hierarchical levels. What is lacking is a systematic investigation of the mechanical properties of enamel on at least four hierarchical length scales which are namely: macroscopic scale $(1-5 \mathrm{~mm})$, several prisms $(\approx 50 \mu \mathrm{m})$, one prism $(\approx 5 \mu \mathrm{m})$ and HAP-rods $(10-50 \mathrm{~nm})$. Indentation with spherical indenters on these different length scales is very promising, because the situation is geometrically self similar and the indenter radii can be adjusted accordingly to the length scales.

This work reports on nanoindentation studies with an approximately $8 \mu \mathrm{m}$ tip radius of a spheroconical indenter positioned in the middle of a rod therefore being on the length scale within one prism. It aims to reveal the elastic-plastic transition of the stressstrain curve on this length scale. The elastic plastic transition under contact loading is especially interesting because it determines the beginning of nonlinear irreversible 
mechanical processes, which are the first step of damage inside the enamel. It is known that the compressive stress that can be exerted on enamel in the intra-oral environment is up to $2.5 \mathrm{GPa}$ [16]. Therefore it is of interest to know whether the elastic/plastic transition on enamel is below or above this stress level. Nonetheless, the authors are aware that enamel might also be considered a visco-elastic material which has the ability of self-recovery after unloading [16]. Whether our results are influenced by a visco-elastic materials response will be discussed in the corresponding chapter.

\section{THEORY: INDENTATION STRESS-STRAIN RELATIONSHIPS}

Indentation stress-strain curves briefly introduced are based on Tabor's theory [17], which was originally developed for metals. There is a possibility to use indentation with spheres to probe the stress-strain response of a material, but it must be pointed out that measured indentation yield points are different from uniaxial mechanical tests due to the complex 3D- stress -distribution around the indent. A spherical indenter in contact with a specimen surface is shown in Fig. 1. The indentation area, $A$ can be related to the indentation radius, $a$, or to the indenter radius, $R$ and the contact depth, $h_{c}$ :

$$
A=\pi a^{2}=\pi\left(2 R h_{c}-h_{c}^{2}\right)
$$

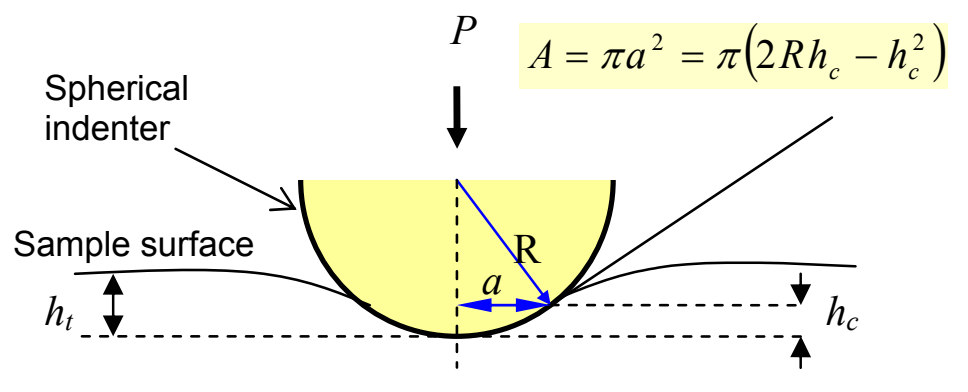

FIGURE 1. A schematic diagram of an elastic contact between an ideal stiff spherical indenter and the surface of an indented specimen. $P$ is the applied load, $R$ is the radius of the spherical indenter and $a$ is the radius of the indentation area. $h_{t}$ is the total indentation depth and $h_{c}$ is the depth of the contact area. $h_{t}=2 * h_{c}$ for elastic response penetration [19].

The classical Hertzian equation for elastic contact of an elastically isotropic material denotes [18]:

$$
h_{t}=\left(\frac{9}{16}\right)^{1 / 3}\left(\frac{P}{E_{r}}\right)^{2 / 3}\left(\frac{1}{R}\right)^{1 / 3}
$$

where $h_{t}$ is the total penetration depth, $P$ is the applied load and $E_{r}$ is the reduced elastic modulus.

In its elastic regime [19] which is usually always the case for the very beginning of the loading: 


$$
h_{c}=\frac{h_{t}}{2}
$$

The elastic modulus, $E$ can be calculated by considering the compliance of the specimen and the indenter tip combined in series,

$$
E=\frac{1-v^{2}}{\left(\frac{1}{E_{r}}-\frac{1-v_{i}^{2}}{E_{i}}\right)}
$$

where $E_{i}, E$ and $v_{i}, v$ are elastic modulus and Poisson's ratio of diamond indenter and specimen respectively. For the diamond indenter $E_{i}=1140 \mathrm{GPa}$ and $v_{i}=0.07$ are used (Hysitron manual, Hysitron, USA).

In Tabor's theory, the indentation stress is represented by the mean contact pressure, $P_{m}$ :

$$
P_{m}=\frac{P}{A}
$$
regime

By assuming $h_{t}<<\mathrm{R}$, substituting Eq. (1) - (3) into Eq. (5) gives for the elastic

$$
P_{m}=\left(\frac{4 E_{r}}{3 \pi}\right) \frac{a}{R}
$$

The indentation strain, $\varepsilon$ can be approximated as follows [17]:

$$
\varepsilon=0.2 * a / R
$$

\section{MATERIALS AND METHODS}

\section{Specimen Preparation}

An extracted human third molar tooth was utilized for the current study. After disinfection in $0.1 \mathrm{wt} \%$ thymol, the tooth was stored in Hank's Balanced Salt Solution (HBSS, Invitrogen, USA) before sample preparations in order to minimize near surface demineralization and, subsequently, changes in mechanical properties [20]. In order to avoid interindividual variation of properties, all measurements were carried out on the same tooth. The tooth was cut at the junction between crown and root and the root was discarded. The tooth surface facing the root was then glued to a steel core (in the shape of a plunger), which was to be attached with a small polishing holder. Embedding the tooth in epoxy was avoided to prevent tooth dehydration. The cuspal region of the tooth was first polished with an abrasive paper of grit 4000. It was further polished with diamond suspensions of $1 \mu \mathrm{m}$ and then $0.25 \mu \mathrm{m}$. The final polishing step was performed with silica suspension of $0.06 \mu \mathrm{m}$ (Mastermet 2, Bühler, Germany). The polished tooth was then glued face-up on a magnetic plate with hot wax for subsequent investigation with AFM and nanoindentation. The polished tooth surface was investigated where enamel rods were oriented parallel to the nanoindentation direction. 


\section{Equipment and Testing Parameters}

The nanoindentation experiments were performed by using a Triboscope indenter system (Hysitron, USA) mounted with a diamond spheroconical indenter tip (Hysitron, USA). The indenter tip radius was calibrated on a fused quartz sample (Hysitron, USA) $\left(E_{r}=69.6 \mathrm{GPa}\right)$ with 57 loading curves of $P_{\max }$ ranges from 0.1 to $11 \mathrm{mN}$. The initial part of these loading curves $\left(h_{t}<20 \mathrm{~nm}\right)$ were fitted with Eq. (2) to obtain the radius, examples are shown in Fig. 2. Enamel was studied with indentation loads of $5 \mathrm{mN}$ and $11 \mathrm{mN}$, with one loading and unloading cycle in 20 seconds. The corresponding loading rates are $0.5 \mathrm{mN} / \mathrm{s}$ and $1.1 \mathrm{mN} / \mathrm{s}$. The indentations were placed in the middle of the rods in enamel at ambient conditions. Each series of indentations were finished within 8 hours. After each series, the tooth was stored in HBSS overnight for re-hydration. The load-displacement data were used to derive the indentation stress-strain curve, $P_{m}$ versus $\varepsilon$. All result curves consist of 8000 data points.

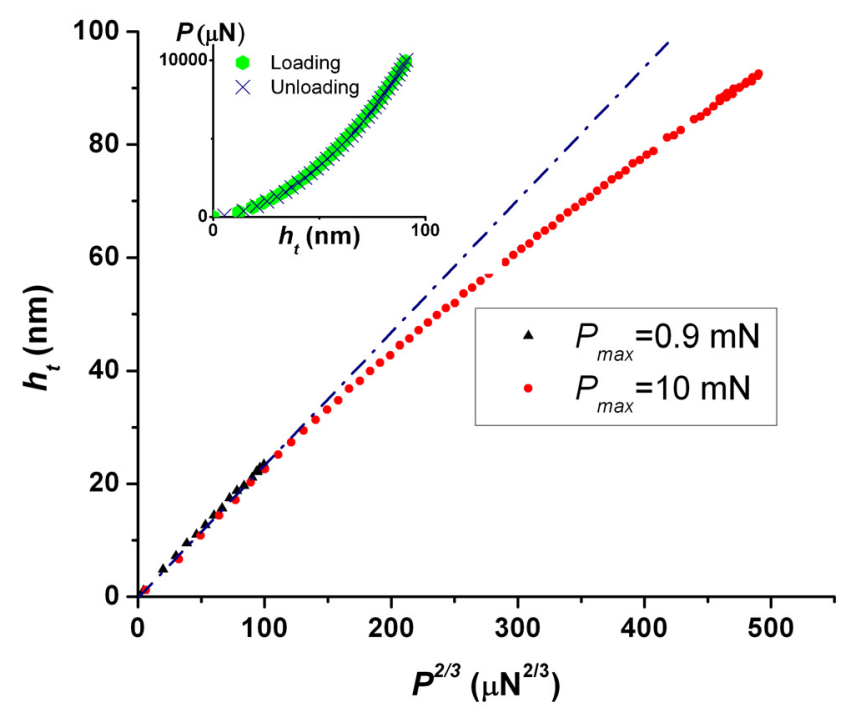

FIGURE 2. The initial parts of two curves with different $P_{\max }(0.9$ and $10 \mathrm{mN})$ show identical linear behavior up to $h_{t}=20 \mathrm{~nm}$. However, the $P_{\max }=10 \mathrm{mN}$ curve deviates from the linear relation at a higher total penetration depth. Hence, only data points of $h_{t}<20 \mathrm{~nm}$ are used for the calibration of indenter radius which gives $\mathrm{R}=8.3 \pm 0.9 \mu \mathrm{m}$ (Eq. (2)). (Inset: the load-displacement curve with $P_{\max }=10 \mathrm{mN}$. The unloading curve overlaps with the loading curve, thus indicates no or negligible plasticity). Therefore the deviation from the linear relation mentioned earlier is unlikely to be caused by plastic deformation of fused quartz.)

\section{RESULTS}

In order to calibrate the indenter radius, $h_{t}$ versus $P^{2 / 3}$ was recorded on fused quartz in the elastic regime. For a constant radius $\mathrm{R}$, a linear relationship is expected according to Eq. (2). The plot of $h_{t}$ versus $P^{2 / 3}$ shows that the curve deviates from the linear relation for $h_{t}>20 \mathrm{~nm}$ (Fig. 2). Consequently, only data points of $h_{t}<20 \mathrm{~nm}$ can be consistently described by a spherical indenter tip radius, calculated from Eq. (2). The value is calculated as $\mathrm{R}=8.3 \pm 0.9 \mu \mathrm{m}$ from the 57 calibration loading curves. The 
standard deviation is calculated based on the formula in Tab. 1. For deeper indentation, the spheroconical shape of the tip leads to the deviation from linearity. With $h_{t}=20 \mathrm{~nm}$, $P=900 \mu \mathrm{N}$ (Fig. 2), the contact pressure was $P / \pi^{*} a^{2}=1.7 \mathrm{GPa}$, which is much lower than the indentation yield stress of fused silica. For instance, the indentation yield stress of fused silica was observed as $\approx 9 \mathrm{GPa}$ by using spherical indenter of $\mathrm{R}=7 \mu \mathrm{m}$ [21]. Therefore, the deviation of the measured data from the linear fit in Fig. 2 is interpreted as a change of the tip shape rather than inelastic deformation of fused silica.

After the last polishing step, the achieved surface roughness of enamel is less than $1 \mathrm{~nm}$, as shown in Fig. 3. The surface roughness, RMS is calculated based on the equation $R M S=\sqrt{\sum\left(Z_{i}\right)^{2} / N}$, where $Z_{i}$ are the measured heights of every pixel and $N$ is the total number of measured heights (pixels). Typical load-penetration curves with maximum loads of $5 \mathrm{mN}$ and $11 \mathrm{mN}$ are shown in Fig. 4. Since the loading paths from both maximum loads are identical up to $5 \mathrm{mN}$, they were combined in the result analysis. The maximum loads correspond to the total penetration depth, $h_{t}$ of around 60 $\mathrm{nm}$ and $100 \mathrm{~nm}$. The very beginning of the curves $\left(h_{t}<1 \mathrm{~nm}\right)$ is discarded due to excessive data fluctuation. The inset in Fig. 5 shows a loading and unloading curve with $P_{\max }=0.1 \mathrm{mN}$, with a very small hysteresis of $\leq 0.5 \mathrm{~nm}$ which is less than $10 \%$ of the total $h_{t}$ analyzed.

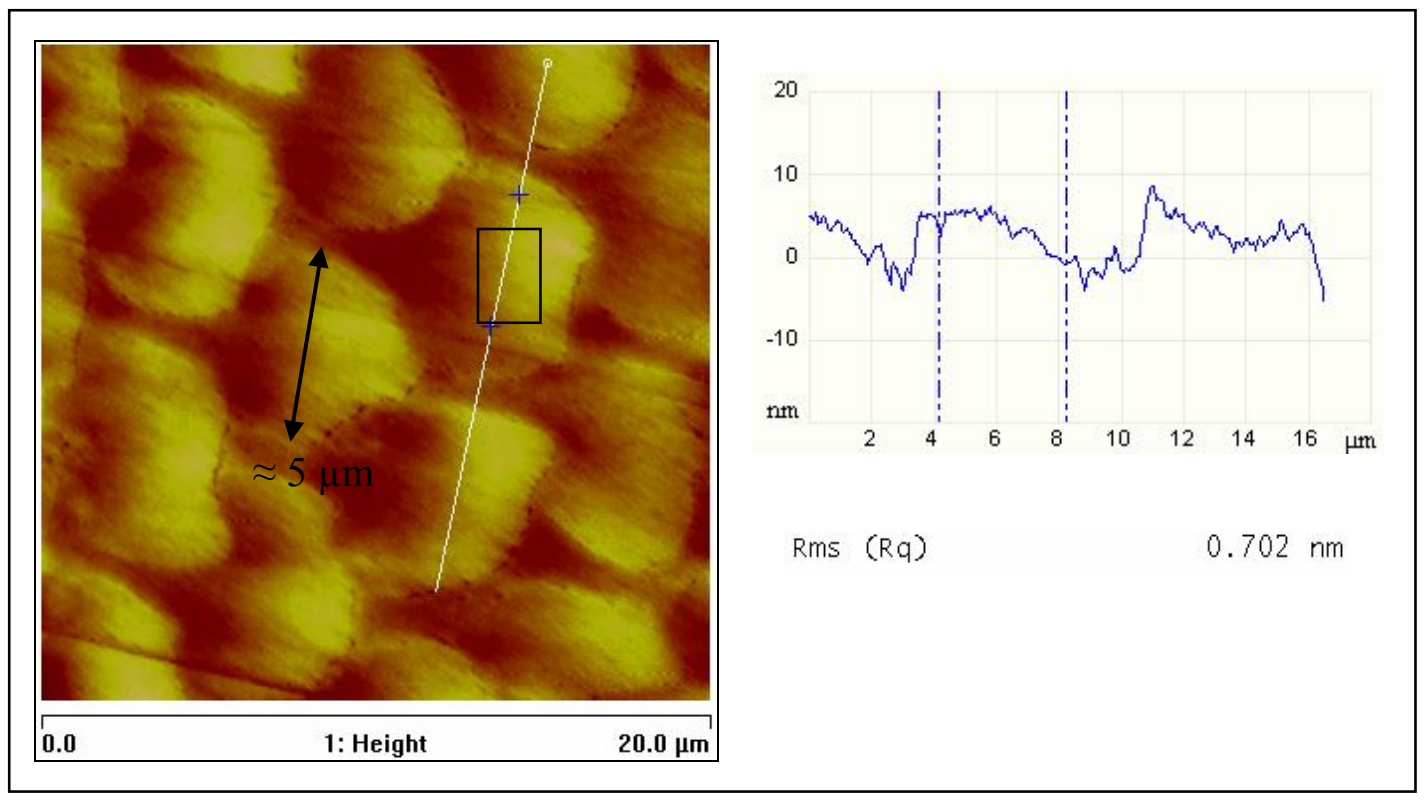

FIGURE 3. An AFM topography image (pixels: $512 \times 512$ ) shows the keyhole-like structures of cross-sectioned enamel rods $(\approx 5 \mu \mathrm{m}$ in width) on a well-polished enamel surface. Black rectangular box is the area chosen for roughness analysis (RMS $<1 \mathrm{~nm}$ ). The topography profile on the right is the cross-section corresponding to the white line on the left.

As shown in Fig. 1 the contact area for indentation can be calculated from the known indenter radius, $\mathrm{R}$ and contact depth $h_{c}$ by Eq. (1). Additionally, in the elastic regime with $h_{t}=2 h_{c}$, we get $A\left(h_{t}\right)=\pi\left(R^{*} h_{t}-h_{t}{ }^{2} / 4\right)$. The mean pressure, $P_{m}$ can be calculated by dividing the load, $P$ at a particular point by its indentation area, $A$. The indentation radius, $a$ can be calculated from known $A$, where $a / R$, thus $\varepsilon$ can be obtained 
accordingly. $P_{m}$ versus $\varepsilon$ is plotted and shown in Fig. 5. We estimate the indentation yield point when the curve deviates from linearity. The plot reveals a yield point approximately at $\sigma_{Y}=1.6 \pm 0.1 \mathrm{GPa}$ and $\varepsilon_{Y}=0.6 \pm 0.05 \%$. It corresponds to $h_{\tau} \approx 7 \mathrm{~nm}, P \approx 280$ $\mu \mathrm{N}$ and $a \approx 250 \mathrm{~nm}$. The data in Fig. 5 are ony plotted to $\varepsilon=1 \%$ because this corresponds to $h_{t}=20 \mathrm{~nm}$, the calibration depth of the indenter. Beyond that our evaluation is not applicable due to the spheroconical shape of the indenter. When the curve in Fig. 5 is plotted with $\mathrm{R}=7.34 \mu \mathrm{m}$ and $\mathrm{R}=9.19 \mu \mathrm{m}$, corresponding to the standard deviation of the indenter radius $\mathrm{R}=8.3 \pm 0.9 \mu \mathrm{m}$, the observed indentation yield points are $\sigma_{Y}=1.7 \mathrm{GPa}$, $\varepsilon_{Y}=0.65 \%$ and $\sigma_{Y}=1.4 \mathrm{GPa}, \varepsilon_{Y}=0.55 \%$ accordingly.

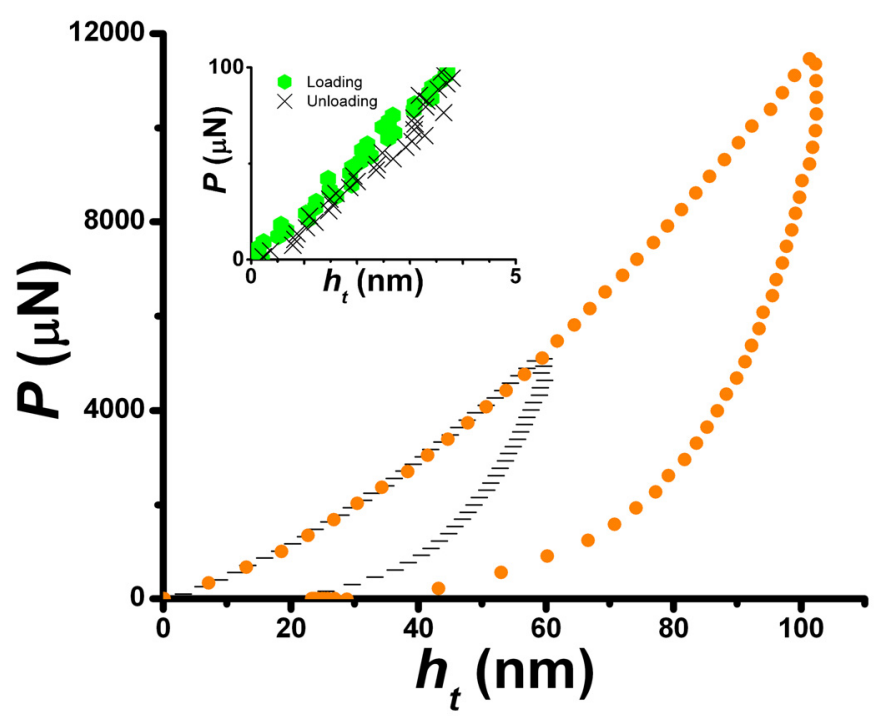

FIGURE 4. Indentation loading and unloading curves with $P_{\max }=5 \mathrm{mN}$ and $P_{\max }=11 \mathrm{mN}$. The loading paths of both curves up to $5 \mathrm{mN}$ are identical within the resolution of our system. (Inset: a loading and unloading curve with $P_{\max }=0.1 \mathrm{mN}$ that shows a very small hysteresis of $\leq 0.5 \mathrm{~nm}$ which is less than $10 \%$ of the total $h_{t}$ analyzed).

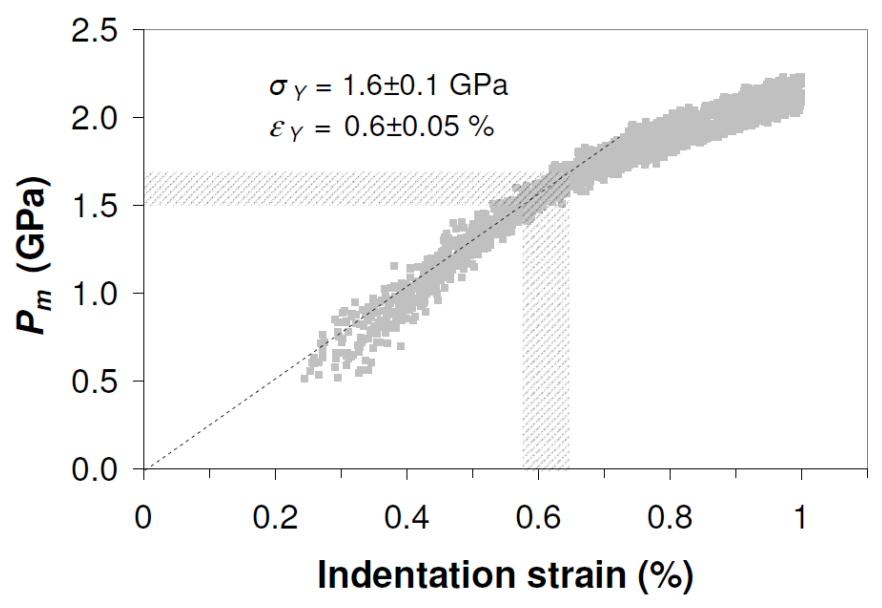

FIGURE 5. $P_{m}$ versus $\varepsilon$ curve for enamel with a spheroconical indenter with tip radius $8.3 \mu \mathrm{m}$. An indentation strain of $1 \%$ corresponds to approximately $20 \mathrm{~nm}$ total penetration depth, beyond this point the indenter is not spherical anymore. 
From Eq. (2), $E_{r}$ can be calculated as $120 \mathrm{GPa}$. By taking the Poisson's ratio of human enamel 0.28 [22], the $E$ is calculated as $123 \mathrm{GPa}$ from Eq. (4).

\section{DISCUSSIONS}

In previous studies by $\mathrm{He}$ and Swain, the indentation stress-strain relationship for enamel was determined [15]. Due to the high load used, their results were most probably beyond the elastic regime even by using a blunt spherical indenter of $R=10$ $\mu \mathrm{m}$. Their indentation stress-strain curve is included in Fig. 6 .

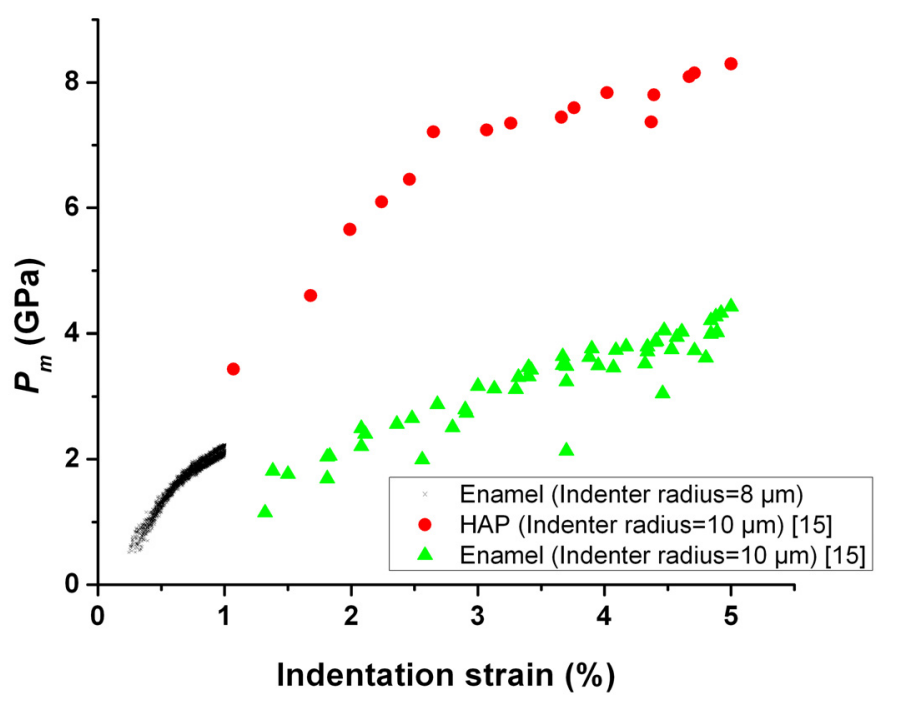

FIGURE 6. The enamel indentation stress-strain curve of the present research is plotted together with enamel and HAP curves from a previous research $(\mathrm{P}=1-400 \mathrm{mN})$ [15].

Since the elastic-plastic transition happens within the first second of the present experiment, it is not likely that creep affects this result. In a recent study by Guidoni et al. [23], the creep data of enamel shows $0.33 \mathrm{~nm} / \mathrm{s}$ under a constant load of $5 \mathrm{mN}$ using a Berkovich indenter. Such creep effect is expected to be even less significant for an 8 $\mu \mathrm{m}$ indenter used in this study. After the yield point, enamel softens. A similar behavior was also observed by Staines et al. [13]. However, this trend is in contradiction with the previous observations in macro-scale tests of whole tooth/enamel, where materials harden after the proportional limit [7-9]. It is most probably that different mechanisms are involved to deform enamel at different length scales. In this study, the contact radius of $250 \mathrm{~nm}$ reached at the indentation yield point indicates that the contact area involves some hundreds of hydroxyapatite crystallites. The involved length scale is still within an enamel rod. The exact reason inducing such a transition is unclear. If viscous processes are excluded due to the short loading times as discussed above only the following mechanisms remain. These are the plastic deformation of the hydroxyapatite crystallites based on dislocation movement or the non-linear extension of the organic layers such as unfolding of the proteins or breaking of so-called sacrificial bonds [24]. As can be seen in Fig. 6 the indentation elastic/plastic transition in pure HAP happens at approximately $7 \mathrm{GPa}$ and is most probably attributed to dislocation motion. Therefore it may be 
concluded that an indentation elastic/plastic deformation at much lower stresses is controlled by the plastic deformation of the soft organics inside the enamel. Another possibility is the beginning of damage in terms of cracking. Detailed investigations of the surface of enamel with high resolution AFM around indentations by a cube corner indenter did not reveal any kind of cracking. As a consequence this possibility is excluded in the further discussion.

The shear strain in the protein layer, $\gamma_{p}$ can be calculated using a model by $\mathrm{He}$ and Swain [25]:

$$
\gamma_{p}=\frac{\left(h_{m}+h_{p}\right) \tan \theta}{h_{p}}
$$

with the shear strain $\gamma_{p}$ in the protein layer, $h_{m}$ and $h_{p}$ the thickness of the hydroxyapatite crystallites and protein layer, $\theta$ the contact angle between the indenter and the surface (Fig. 7). Since $\tan \theta=a /$ R, rearranging Eq. 8 gives

$$
a=\gamma_{p} R \frac{h_{p}}{h_{m}+h_{p}}
$$

In order to calculate the contact radius for the beginning of non-linear shear in the protein layer we use a generally considered protein's elastic shear strain limit of 0.1 . When $h_{p}$ is taken as $2 \mathrm{~nm}, h_{m}$ is taken as $25 \mathrm{~nm}$ and $70 \mathrm{~nm}$ (corresponding to thickness and width of hydroxyapatite crystallites), the corresponding two contact radii are calculated as $61 \mathrm{~nm}$ and $23 \mathrm{~nm}$ and are much smaller than the experimentally measured value $a \approx 250 \mathrm{~nm}$. Therefore, a substantial amount of protein already shears above the elastic limit when the microscopic non-linearity in this study is detected.

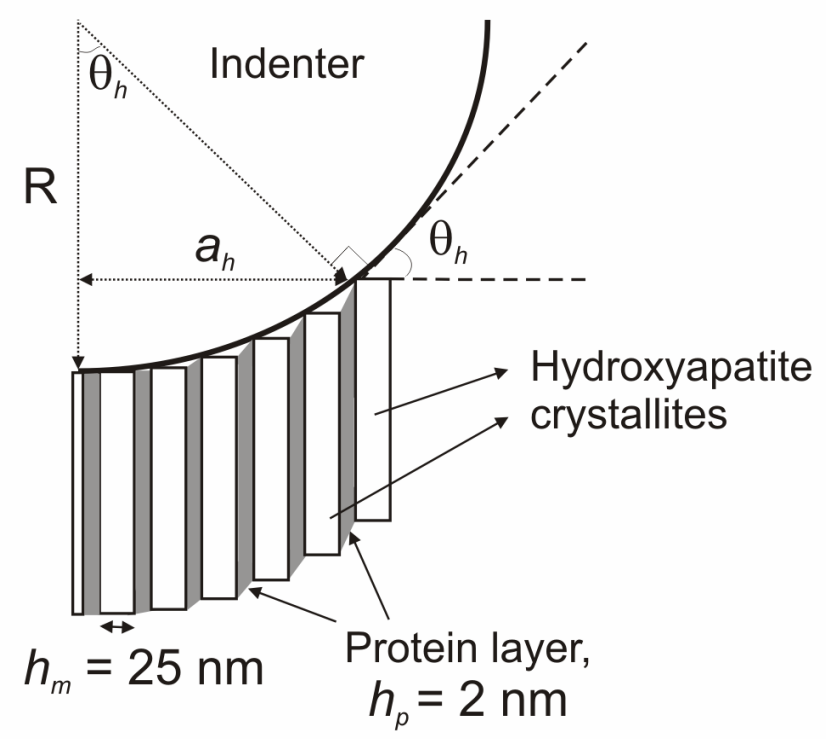

FIGURE 7. Schematic illustration of enamel deformation induced by a spherical indenter. It is assumed that the deformation is completely due to the shear deformation of the protein layer.

Enamel's indentation yield strain determined in this study is in reasonable agreement with calculated values from previous studies. The property does not seem to be sensitive to the size effect. Schneider et al. [26] presented a viscous flow model for enamel, where the hydroxyapatite crystallites and organics are modeled as a 3D structure of oriented rigid rods within a viscous fluid. Based on this model, calculations 
of the maximum amount of inelastic creep strain are about $4 \%$. So, an indentation yield strain of $\varepsilon_{Y}=0.6 \%$ shows that the organics still exist in the channels between the crystallites at the indentation yield point. Based on the indentation stress-strain curve in Fig. 5, when the maximum compressive stress occurs in oral environment, which is around $2.5 \mathrm{GPa}$, the strain experienced by enamel is slightly beyond $1 \%$ and is still below the maximum strain value derived from the viscous flow model. Hence, the organics should never be squeezed out completely from the channels among crystallites (and maintain the toughness of enamel).

The indentation yield stress of enamel from this study is significantly higher than the stresses at the proportional limit from previous studies, which are at larger length scales. This might be attributed to better microstructure uniformity and absence of large flaws when only a small volume is involved. The potential effect of drying on the indentation yield stress in the present study is also considered. In a recent study by Baldassarri et al., the microhardness of enamel is shown to increased by just $2 \%$ after a flash-freezing followed by dehydration under vacuum for 2 days [27]. Hence, it is supposed that the indentation yield stress might not show considerable difference in comparison to measurements in a liquid environment. The potential effect of drying on the measured elastic modulus is also evaluated. In a recent study, Guidoni et al. utilized nanoindentation to compare enamel's indentation modulus under "wet" (immersed in HBSS solution) and "dry" (dried in laboratory air for a period longer than $12 \mathrm{~h}$ ) condition [23]. It is shown in their study that the influence of environment on the properties become less significant from sharp to blunt indenters. Quantitatively, the elastic modulus of dried sample increase by $120 \%$ for cube corner indenter $\left(35.26^{\circ}\right)$, but decrease by $12 \%$ for $45^{\circ}$ pyramidal indenter and only $<4 \%$ for berkovich indenter. Such changes are expected to be even less significant for $8 \mu \mathrm{m}$ spheroconical indenter used in this study.

From a continuum mechanics point of view, the measured elastic modulus should be independent of indentation depth and the type of indenter used. However, this must not necessarily be true for composite hierarchy of enamel structure. For the same type of indenter, the deeper the contact depth, the bigger the indentation area, and at certain points, the mechanical behavior of a hierarchical material is expected to change. For the same penetration depth, the indentation area varies according to the type of indenter too. To our knowledge for indenter radii in the $10 \mu \mathrm{m}$ range the present study is the first one to evaluate the elastic modulus of human enamel by using the loading part of the indentation curve applying Eq. (2). He and Swains study with an indenter of similar size used the unloading part and was consequently at higher penetration depths [28]. Therefore much larger contact areas were covered. This may be one of the reasons why slightly lower elastic moduli have been measured in comparison to our results.

Elastic modulus has been reported within the range of 74-130 GPa when the enamel rods were oriented parallel to the indentation, regardless of the type of indenters used [13,20,29-35]. The different Poisson's ratio used in these studies is one of the sources of variations of these values. The $E$ values from the present study are slightly lower than the results from nanoindentation measurements of a hydroxyapatite single crystal, $E=162 \pm 1.9 \mathrm{GPa}$ where the test direction was normal to the basal plane and $E=127.2 \pm 10.4 \mathrm{GPa}$ for the test direction being normal to the prism plane [36]. It should be kept in mind that the present measurement results are mean values of possible defective hydroxyapatite at different orientations. Though enamel's elastic modulus is only marginally altered by the low organic and water content $(\approx 4 \mathrm{wt} \%)$, its resistance 
towards permanent deformation is greatly reduced compared to pure hydroxyapatite. The indentation yield stress of enamel, $1.6 \pm 0.1 \mathrm{GPa}$ is about 4.5 times smaller than the estimated indentation yield stress of hydroxyapatite, $\sigma_{Y H A P} \approx 7 \mathrm{GPa}$ from nanoindentation measurements by $\mathrm{He}$ and Swain [15] (Fig. 6). The yield strain of enamel is approximately 5 times smaller than pure hydroxyapatite $\left(\varepsilon_{Y H A P} \approx 2 \%\right)$ (Fig. 6). This is in accordance with previous studies that the small percentage of organics and water play an important role in regulating enamel's mechanical characteristics [15,37].

\section{CONCLUSIONS}

The very first part of the nanoindentation loading curve was evaluated in order to determine the indentation elastic response and the cross over to plastic behavior of human enamel at a contact length scale of about $0.5 \mu \mathrm{m}$. The indentation elastic-plastic transition of enamel was determined to be $\sigma_{Y}=1.6 \pm 0.1 \mathrm{GPa}$ and $\varepsilon_{Y}=0.6 \pm 0.05 \%$ at a contact radius of approximately $250 \mathrm{~nm}$ and a total penetration depth of $7 \mathrm{~nm}$. We believe that the understanding of this transition is important because loading beyond it would introduce irreversible process such as wear and fatigue. This information could be used to define the mechanical criteria of newly developed novel bio-mimetic materials. Due to the hierarchical structure of enamel, it is important to correlate the measured values with the contact length scale. $\sigma_{Y}$ is significantly higher than the values of macro-scale tests but on the other hand only about one third of the yield stress of synthetic hydroxyapatite. Further investigation is underway to understand the elasticplastic transition at different length scales of enamel and the involved deformation mechanisms.

\section{ACKNOWLEDGEMENTS}

The authors wish to express gratitude to German Research Foundation for financial support. Special thanks are extended to Prof. Mike Swain and Dr. Li Hong He from the University of Sydney for data comparison and valuable discussions.

\section{REFERENCES}

1. Healy KE. Dentin and Enamel. In: Black J, Hastings, G, editors. Handbook of biomaterials properties. Springer-Verlag; 1998, p. 25.

2. Gray H, Bannister LH, Berry MM, Williams PL. Gray's Anatomy: The Anatomical Basis of Medicine \& Surgery. 38th ed. New York: Churchill Livingstone; 1995, p. 1710.

3. Frazier PD. Adult human enamel: an electron microscopic study of crystallite size and morphology. J Ultrastruct Res, 1968; 22:1-11.

4. Daculsi G, Kerebel B. High-resolution electron microscope study of human enamel crystallites: size, shape, and growth. J Ultrastruct Res, 1978; 65:163-172.

5. Daculsi G, Menanteau J, Kerebel LM, Mitre D. Length and shape of enamel crystals. Calcif Tissue Int, 1984; 36:550-555.

6. Nanci A. Ten Cate's oral histology: development, structure, and function. St. Louis: Mosby; 2003. 
7. Neumann HH, DiSalvo NA. Compression of teeth under the load of chewing. J Dent Res, 1957; 36:286-290.

8. Haines DJ, Berry DC, Poole DFG. Behavior of tooth enamel under load. J Dent Res, 1963; 42:885-888.

9. Fox PG. The toughness of tooth enamel, a natural fibrous composite. J Mater Sci, 1980; 15:3113-3121.

10. Stanford JW, Paffenbarger GC, Kumpula JW, Sweeney WT. Determination of some compressive properties of human enamel and dentin. J Am Dent Assoc, 1958; 57:487-495.

11. Stanford JW, Weigel KV, Paffenbarger GC, Sweeney WT. Compressive properties of hard tooth tissues and some restorative materials. J Am Dent Assoc, 1960; 60:746-756.

12. Craig, RG, Peyton FA, Johnson DW. Compressive properties of enamel, dental cements, and gold. J Dent Res, 1961; 40:936-945.

13. Staines M, Robinson WH, Hood JAA. Spherical indentation of tooth enamel. J Mater Sci, 1981; 16:2551-2556.

14. Timoshenko SP, Goodier JN. Theory of Elasticity. 3rd ed. New York: McGraw-Hill; 1970, p. 409.

15. He LH, Swain MV. Enamel - a "metallic-like" deformable biocomposite. J Dent, 2007; 35:431-437.

16. He LH, Swain MV. Review: Understanding the mechanical behavior of human enamel from its structural and compositional characteristics. J Mech Behav Biomed Mater, 2008; 1:1829.

17. Tabor D. The Hardness of Metals. Oxford: Clarendon Press; 1951.

18. Hertz HR. Miscellaneous Papers. London: Macmillan; 1896.

19. Fischer-Cripps AC. Introduction to contact mechanics (Mechanical engineering series). New York: Springer-Verlag Inc.; 2000, p. 42.

20. Habelitz S, Marshall GW, Balooch M, Marshall SJ. Nanoindentation and storage of teeth. J Biomech, 2002; 35:995-998.

21. Bushby AJ, Dunstan DJ. Plasticity size effects in nanoindentation. J Mater Res, 2004; 19:137-142.

22. Waters NE. Some mechanical and physical properties of teeth. In: Vincent JFV, Currey JD, editors. The Mechanical Properties of Biological Materials. Cambridge: Cambridge University Press; 1980, p. 99-136.

23. Guidoni GM, He LH, Schöberl T, Jäger I, Dehm G, Swain MV. Influence of the indenter tip geometry and environment on the indentation modulus of enamel. J Mater Res, 2009; 24:616-625.

24. Fantner GE, Hassenkam T, Kindt JH, Weaver JC, Birkedal H, Pechenik L, Cutroni JA, Cidade GAG, Stucky GD, Morse DE, Hansma, PK. Sacrificial bonds and hidden length dissipate energy as mineralized fibrils separate during bone fracture. Nature Materials, 2005; 4:612-616.

25. He LH, Swain MV. Contact induced deformation of enamel. Appl Phys Lett, 2007; 90: 171916.

26. Schneider GA, He LH, Swain MV. Viscous flow model of creep in enamel. J Appl Phys, 2008; 103:014701.

27. Baldassarri M, Margolis HC, Beniash E. Compositional determinants of mechanical properties of enamel. J Dent Res, 2008; 87:645-649.

28. He LH, Fujisawa N, Swain MV. Elastic modulus and stress-strain response of human enamel by nano-indentation. Biomaterials, 2006; 27:4388-4398.

29. Xu HHK, Smith DT, Jahanmir S, Romberg E, Kelly JR, Thompson VP et al.. Indentation damage and mechanical properties of human enamel and dentin. J Dent Res, 1998; 773:472480.

30. Mahoney E, Holt A, Swain M, Kilpatrick, N. The hardness and modulus of elasticity of primary molar teeth:an ultra-micro-indentation study. J Dent, 2000; 28:589-594. 
31. Fong H, Sarikaya M, White SN, Snead ML. Nano-mechanical properties profiles across dentin-enamel junction of human incisor teeth. Mater Sci Eng C, 2000; 7:119-128.

32. Habelitz S, Marshall SJ, Marshall GW, Balooch M. Mechanical properties of human dental enamel on the nanometre scale. Arch Oral Biol, 2001; 46:173-183.

33. Ge, J, Cui FZ, Wang XM, Feng HL. Property variations in the prism and the organic sheath within enamel by nanoindentation. Biomaterials, 2005; 26:3333-3339.

34. Zhou J, Hsiung LL. Depth-dependent mechanical properties of enamel by nanoindentation. J Biomed Mater Res A, 2007; 81:66-74.

35. Braly A, Darnell LA, Mann AB, Teaford MF, Weihs TP. The effect of prism orientation in the indentation testing of human molar enamel. Arch Oral Biol, 2007; 52:856-860.

36. Viswanath B, Raghavan R, Ramamurty U, Ravishankar N. Mechanical properties and anisotropy in hydroxyapatite single crystals. Scripta Materialia, 2007; 57:361-4.

37. Spears IR. A three-dimensional finite element model of prismatic enamel: a reappraisal of the data on the Young's modulus of enamel. J Dent Res, 1997; 76:16907. 